\title{
Body weight and preference for a free-operant conflict situation
}

\author{
D. A. THOMAS and S. J. WEISS \\ The American University, Washington, District of Columbia
}

\begin{abstract}
Six male food-restricted hooded rats were trained to press a bar on a two-component multiple schedule in which a response chain enabled the rats to control which component was operating (switchable-multiple schedule). The reinforcement density was several times higher in one component, but barpress responses were intermittently punished with foot shock in this conflict component. On this switchable-multiple schedule, the rats responded at a higher rate in the unshocked component and stayed in this component most of each session. After 5 months, however, 2 rats began spending most of each session in the shocked component. To test whether a deprivation manipulation would influence preference for the shock-food conflict component as it does final spatial distance from the goalbox in an approach-avoidance runway conflict situation, the weights of these 2 rats were gradually increased and then gradually decreased in an ABA design. When their weights were increased, these rats more than quadrupled their time in the unshocked component. This was reversed with weight reduction. These findings support the contention that the temporal resolution of conflict in the free-operant choice paradigm is analogous to the spatial resolution of conflict in a runway.
\end{abstract}

Preference has been studied in a variety of behavioral paradigms, but there is little data on the relation between measures of preference in free-operant and in runway paradigms. A group of rats from a recent study (Thomas, Weiss, \& Schindler, 1990) produced the opportunity to examine an aspect of this issue. These rats responded on a two-component multiple schedule. In one (the conflict) component, barpresses were richly reinforced with food, but they were also punished with shock. In the other (the unshocked) component, presses were not punished, but food reinforcement was much less frequent. This type of multiple schedule, which contains one conflict component and one component that does not include a punishment contingency, was introduced by Geller and Seifter (1960) as a baseline against which to test the antianxiolytic properties of drugs. In the present research, a GellerSeifter conflict schedule was used, but the subjects were given the opportunity to choose the component of the multiple schedule that was operating. This switchablemultiple schedule was described by Thomas and Weiss (1986).

For 5 months of training, all 6 rats spent the majority of virtually every session in the safe component. They also responded more rapidly in that component than they did in the conflict component. However, after 5 months, 2 rats (Rats 105 and 110) began to spend the major part of each session in the punishment component, while con-

Reprint requests should be sent to $D$. A. Thomas, who is now at the following address: Neurobiology and Anesthesiology Branch, National Institute of Dental Research, National Institutes of Health, Building 30, Room B20, Bethesda, MD 20892. tinuing to barpress slowly in this component (see Figure 1). This created the opportunity for us to determine whether the component preference of Rats 105 and 110 could be made comparable to that of the other 4 rats through the manipulation of a variable proven effective at influencing approach-avoidance conflict resolution in the runway.

In runway studies of approach-avoidance behavior, food deprivation has been found to increase goalbox approach, despite aversive stimulus presentation (cf. Miller, 1959). This deprivation-level effect on approach-avoidance behavior has been attributed to interacting approach and avoidance motivational gradients (see, e.g., Brown, 1942; Hull, 1952; Miller, 1944). In the free-operant conflict situation, however, even severe increases in a rat's food deprivation have been found to be of only small consequence in increasing punished response rates (Cook \& Davidson, 1973; Margules \& Stein, 1967). This apparently contradicts findings from runway studies of approachavoidance behavior, in which increased deprivation has been found to greatly increase the tendency to approach a goalbox despite a punishment contingency.

A theory related to preference may help resolve this paradox (Coombs \& Avrunin, 1977). An assumption of this theory of single-peaked preference functions is that runway behavior is a spatial measure of preference. If this is true, response rate in the free-operant setting may not be an accurate analogue of runway behavior. For example, there are schedules that produce high response rates with low rates of reinforcement and others that produce low response rates with high rates of reinforcement (Ferster \& Skinner, 1957). However, the time a subject chooses to remain in components may be a temporal analogue to 
the spatial variable of position in a runway, with both being measures of preference. Although neither Margules and Stein (1967) nor Cook and Davidson (1973) could address this issue because their rats could not control which components operated, both component preference and response rates could be simultaneously measured with our switchable-multiple schedule.

The present research involved systematically changing the body weights of Rats 105 and 110 and measuring the effects on component preference and response rates. The question of interest was whether the effect of deprivation on time spent in components would be consistent with the effect of deprivation on goalbox approach-avoidance behavior in the runway situation. That is, would higher body weights reduce the tendency of the subjects to come in contact with aversive stimuli in order to get food? Conversely, would lower body weights increase the subjects' tendency to come in contact with the aversive stimuli in order to get food?

\section{METHOD}

\section{Subjects}

Six male Long-Evans hooded rats obtained from Blue Spruce Farms served as the subjects. The rats were individually housed and received free access to water in their home cages. During baseline training, their food was restricted to maintain them at about $80 \%$ of their free-feeding weights. Following each session, they received the remainder of their daily food allotment. The rats were trained from four to six times a week. Although all rats underwent the baseline training, 4 rats $(103,107,109$, and 114) were not used in the final experimental manipulation. These rats, unlike Rats 105 and 110 , preferred the unshocked component (see Figure 1). Performing an opposite symmetric weight manipulation to that used for Rats 105 and 110 (e.g., substantially lowering, and then raising, these rats' weights) would have involved reducing them well below $80 \%$ of their free-feeding weights, which was not desired.

\section{Apparatus}

The rats were trained and tested in three similar operant training chambers described elsewhere (Thomas et al., 1990). A microswitch bar was located on the right side of the front wall, with a food trough on the left side. A chain attached to a microswitch extended into the chamber from a ventilation hole located in the center of the ceiling.

The $2000-\mathrm{Hz}, 90-\mathrm{dB}$ discriminative stimulus $\left(\mathrm{S}^{\mathrm{D}}\right)$ of tone was presented through a speaker mounted above the chamber. The light $S^{D}$ was generated by two $15-\mathrm{cm}$ showcase, $25-\mathrm{W}, 120-\mathrm{V}$ bulbs. The training chamber and its associated stimulus-presentation devices were enclosed within a sound-attenuation chest described elsewhere (Weiss, 1970).

Reinforcers were 45-mg Noyes food pellets. Footshocks were $0.5 \mathrm{sec}$ and were produced by solid-state constant-current scramble shockers. Shock intensities were titrated for each rat to produce desired effects on response rates. Sessions were run and data were collected with a PDP-8 computer running a SKED program.

\section{Procedure}

The rats were trained to approach the food trough when the feeder was activated, then shaped to press the bar for food. Next, they were trained to respond on a variable-interval 30-sec (VI 30-sec) schedule, in which the first response after a variable period averaging $30 \mathrm{sec}$ from the last reinforced response was reinforced. Half of the rats (Rats 103, 105 , and 107) received initial training with the showcase lights on and the others (Rats 109, 110, and 114) with the tone on. Over the next 4 months, the rats were advanced from this VI 30-sec schedule, to a multiple (VI 30-sec, VI 90-sec) schedule, to a multiple (VI 30-sec + shock, VI 90-sec) schedule, and finally to a switchable-multiple (VI 30 sec + shock, VI 90-sec) schedule. Throughout this training, behavioral
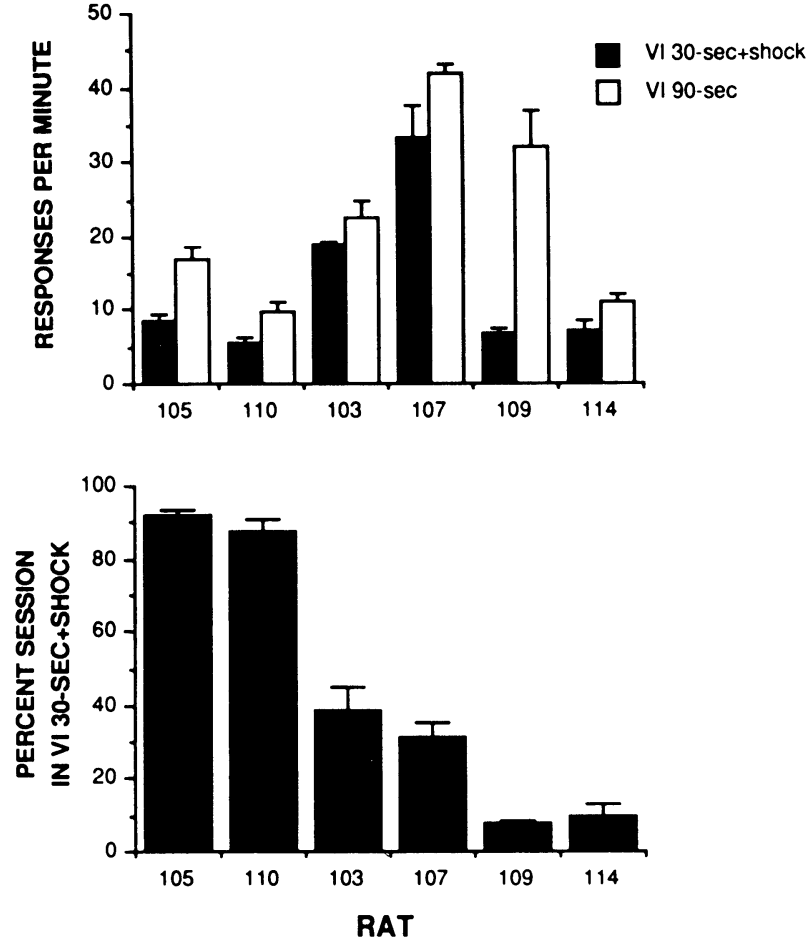

Figure 1. Upper graph: Mean responses per minute in the VI 30 sec + shock and VI 90-sec components, for 6 rats after approximately 5 months of training. Data were obtained from three consecutive sessions. Note that, in all cases, the rats were responding more frequently in the VI 90-sec components. T-bars = one $S E M$. Lower graph: Mean percent of sessions spent in VI 30-sec + shock components. Note that only Rats 105 and 110 tended to spend the majority of the sessions in the VI $30-\mathrm{sec}+$ shock components.

stability was defined as no more than $20 \%$ variation in response rate with no obvious trend in either component for 3 days. The rats were advanced from one schedule to the next when their behavior was stable.

On this final switchable-multiple (VI 30-sec + shock, VI 90-sec) schedule, in the conflict component, a VI 30-sec food reinforcement schedule was in effect, and every 10th response, on the average, was punished with foot shock. A VI 90-sec schedule was in effect in the other component. Each component was $250 \mathrm{sec}$, and the components alternated with each other. However, if the chain was pulled, the operating component immediately switched. The only limit on the number of times a rat could switch components was that $0.5 \mathrm{sec}$ had to elapse after one chain pull before the next would switch components. This restriction was imposed because at times the rats would hang on the chain, and inadvertent chain pulls might have occurred as the rats let go of the chain. Sessions lasted 4,000 sec, and the percentage of the session that rats spent in the VI 30 -sec + shock components was used as a measure of preference. Fifty percent of the session in each component was taken as indicating no preference between them.

The rats were trained on this schedule for 5 months and usually responded at a greater rate and spent most of each session in the VI 90-sec component. Rats 105 (light $=$ VI 30-sec + shock) and 110 (tone $=$ VI 30-sec + shock), however, began to prefer the VI 30-sec + shock component (Figure 1). In the present experiment, we examined the effect of body weight on these rats' component preferences and absolute response rates. First, the weights of Rats 105 and 110 were gradually increased over 12-18 sessions, until they approximated the rats' freefeeding weights. Next, these weights were decreased until the rats' preferences were again stable. The experiment was concluded after a stable effect of decreasing weight on preference was obtained. 


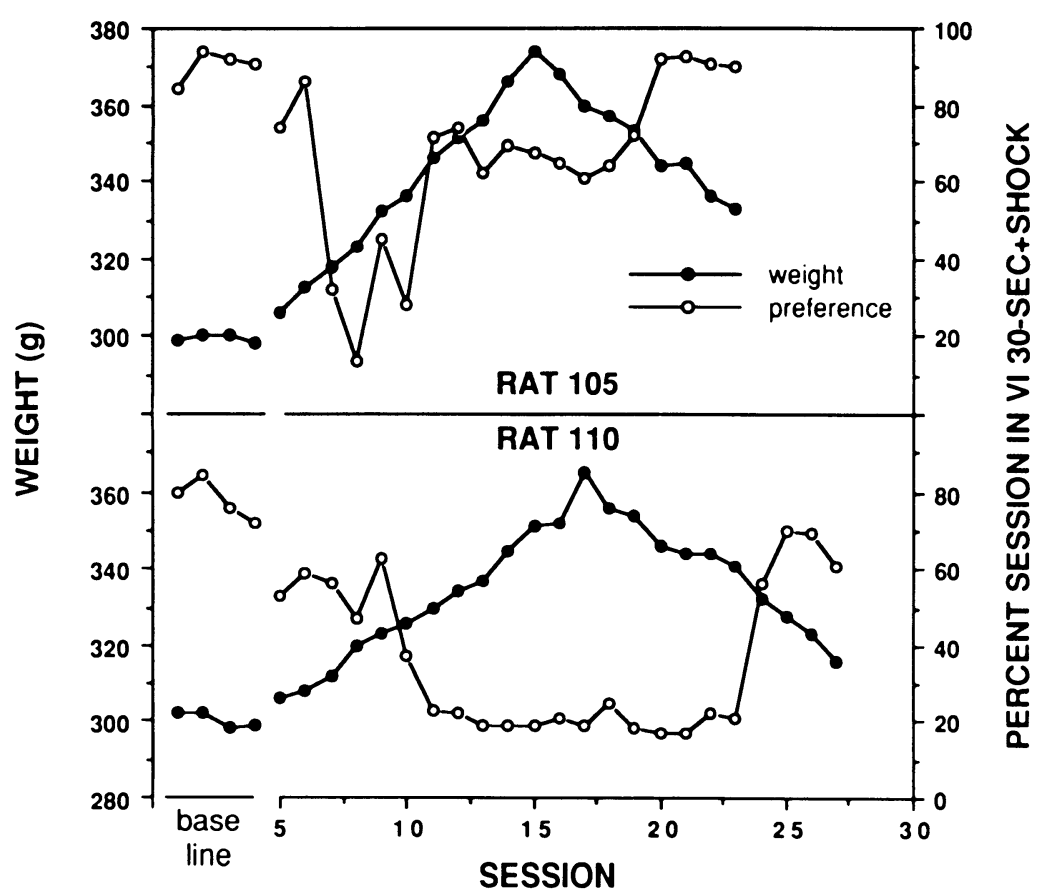

Figure 2. Percent of session spent in the VI 30-sec + shock component across sessions when the weights of Rats 105 and 110 were systematically changed.

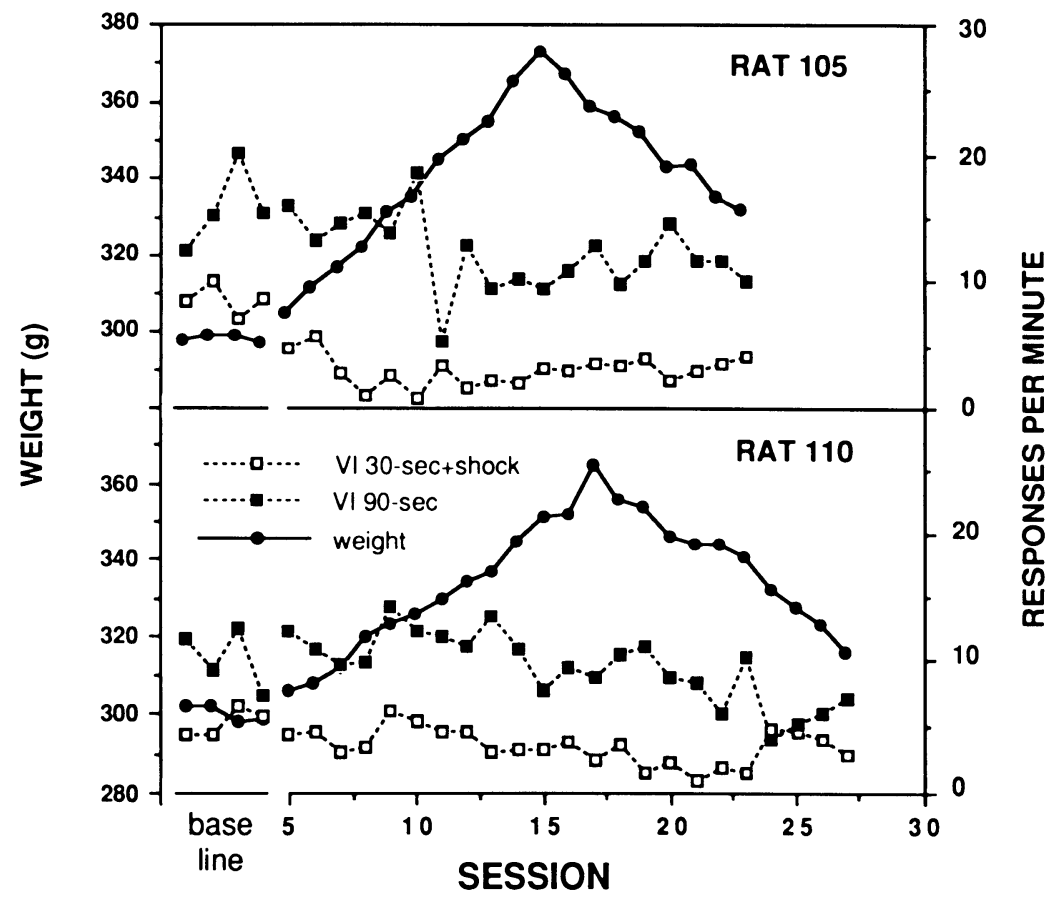

Figure 3. Responses per minute in the VI 30-sec + shock and VI 90-sec components across sessions when the weights of Rats 105 and 110 were systematically changed. 


\section{RESULTS}

Figure 2 shows how the rats' weights were related to their preferences for components. For both rats, as their weights increased, their preferences decreased for the VI 30-sec + shock component. Rats 105 and 110 initially spent $80 \%-95 \%$ of their sessions in the VI $30-$ sec + shock component at their baseline weights of $\sim 300 \mathrm{~g}$. When their weights increased by $8 \%-10 \%$ over baseline, the percent of the sessions they spent in the VI 30-sec + shock component decreased by $60 \%$ (Rat 110 ) to $70 \%$ (Rat 105 ). This meant they were only in the shocked component for about $20 \%$ of each session. This change relative to baseline continued for both rats as their weights were further increased. Rat 110 spent about $20 \%$ of the sessions in the shocked component, whereas Rat 105 spent about $70 \%$. Preference for the VI 30-sec + shock component approached the premanipulation baseline for both rats after their weights were reduced to approximately $90 \%$ of the maximum weights they reached during the weight manipulation.

In Figure 3, body weight is related to the absolute response rates in the shocked and unshocked components for both of the rats. The changes in their rates are not as clearly related to the body weight manipulation as were the changes in component preferences (Figure 2). Body weight was not consistently related to response rate in the unshocked component for either rat. However, the absolute response rate in the shocked component appeared to be inversely related to body weight for both rats, although this relationship was more pronounced for Rat 105 than it was for Rat 110.

\section{DISCUSSION}

In the approach-avoidance conflict situation, an increase in deprivation enhances the likelihood of goalbox approach behavior. In the present study, an inverse relationship between conflict-component preference and body weight in a free-operant situation was found. This demonstrates that spatial resolution of conflict in the runway is affected by a deprivation manipulation in a manner similar to how the temporal resolution of conflict in this free-operant setting is affected.

In comparison with the dramatic effect that the changes in body weight had on conflict-component preference, this manipulation had a relatively small, but consistent, effect on absolute response rates in the conflict component. This small effect on conflict-component response rates is consistent with what was found in similar paradigms by Margules and
Stein (1967) and Cook and Davidson (1973). In these studies, increasing deprivation levels of rats also increased punished responding in a Geller-Seifter conflict paradigm to a small degree. While replicating these findings, the present study demonstrates for the first time that preference, as measured by time in components, is strongly affected by changes in weight in a Geller-Seifter conflict paradigm. Clearly, in this conflict paradigm, response rate is less sensitive to a motivational manipulation than preference is, which is reflected by the rats' decision to remain in each component. Therefore, the switchable-multiple conflict paradigm would be a more complete source of behavioral data than conventional free-operant conflict paradigms in which only response rate is measured.

\section{REFERENCES}

Brown, J. S. (1942). Factors determining conflict reactions in difficult discriminations. Journal of Experimental Psychology, 31, 272-292.

Cook, L., \&Avidson, A. B. (1973). Effects of behaviorally active drugs in a conflict-punishment procedure in rats. In S. Garattini, E. Mussini, \& L. O. Randall (Eds.), The benzodiazepines (pp. 379404). New York: Raven Press.

Coombs, C. H., Avrunin, G. S. (1977). Single-peaked functions and the theory of preference. Psychological Review, 84, 216-230.

Ferster, C. B., SkINNER, B. F. (1957). Schedules of reinforcement. Englewood Cliffs, NJ: Prentice-Hall.

Geller, I., Seifter, J. (1960). The effects of meprobamate, barbiturates, $d$-amphetamine and promazine on experimentally induced conflict in the rat. Psychopharmacologia, 1, 482-492.

Hull, C. L. (1952). Principles of behavior. New Haven, CT: Yale University Press.

Margules, D. L., \& Stein, L. (1967). Neuroleptics vs. tranquilizers: Evidence from animal behavior studies of mode and site of action. In H. Brill, J. O. Cole, P. Deniker, H. Hippius, \& P. B. Bradley (Eds.), Neuropsychopharmacology (pp. 108-120). Amsterdam: Excerpta Medica Foundation.

Miller, N. E. (1944). Experimental studies of conflict. In J. Hunt, (Ed.), Modern learning theory (pp. 1-176). New York: AppletonCentury-Crofts.

Miller, N. E. (1959). Liberalization of basic S-R conceptions: Extensions to conflict behavior, motivation, and social learning. In S. Koch (Ed.), Psychology: A study of a science (Vol. 2, pp. 196292). New York: McGraw-Hill.

ThомAS, D. A., \& WeIss, S. J. (1986, April). Independent measures of time allocation and relative response rates as indicators of preference. Paper presented at the meeting of the Eastern Psychological Association, New York

Thomas, D. A., Weiss, S. J., \& Schindler, C. W. (1990). The effects of chlordiazepoxide and flumazenil on preference for punished and unpunished response alternatives in rats. Psychopharmacology, 102, 333-338.

Weiss, S. J. (1970). An effective and economical sound attenuation chamber. Journal of the Experimental Analysis of Behavior, 13, 37-39.

(Manuscript received February 14, 1991). 